\title{
METAPLASTIC CARCINOMA OF BREAST: A CASE REPORT
}

Prema Devi E1, Susruthan M², C. D. Narayanan³, N. Priyathershini4, J. Thanka ${ }^{5}$

\section{HOW TO CITE THIS ARTICLE:}

Prema Devi E, Susruthan M, C. D. Narayanan, N. Priyathershini, J. Thanka."Metaplastic Carcinoma of Breast: A Case Report". Journal of Evolution of Medical and Dental Sciences 2015; Vol. 4, Issue 23, March 19;

Page: 4052-4057, DOI: 10.14260/jemds/2015/585

ABSTRACT: INTRODUCTION: Metaplastic carcinomas of the breast comprise less than 1\% of all invasive carcinomas. They are a heterogeneous group of malignant breast tumors in which a part or all of carcinomatous epithelium gets converted into a non-glandular (Metaplastic) growth process. ${ }^{1}$ The sarcomatoid element can be bone, cartilage spindle cell component or myxoid changes. ${ }^{2}$ Here, we report a case of metaplastic carcinoma with chondrosarcomatous differentiation which is even more rarer. CASE PRESENTATION: A 48yrs old female had swelling in the left breast for 2months duration. Fine needle aspiration cytology was done for the swelling (M) $6 \times 5 \times 4 \mathrm{~cm}$. An impression of atypical cells seen in cytology was given (Image 1). A modified radical mastectomy was done which showed aninfiltrating carcinoma mixed with heterologous mesenchymal elements which showed areas of cartilage differentiation. A final impression of pT3pN0cM0 nottinghams grade 3 metaplastic carcinoma with chondrosarcomatous differentiation, margins free of tumor was given. DISCUSSION: Metaplastic carcinomas of the breast comprise less than $1 \%$ of all invasive carcinomas. They are a heterogeneous group of malignant breast tumors in which a part or all of carcinomatous epithelium gets converted into a nonglandular (Metaplastic) growth process. ${ }^{1}$ This case is presented here due to its rarity and hence reporting this will help surgeons in diagnosis.

KEYWORDS: Breast, Metaplastic carcinoma, Chondrosarcomatous differentiation.

INTRODUCTION: In breast, the incidence of cartilaginous lesions are rare. Less than 5\% of breast carcinomas are transformed as a part or whole into mesenchymal histological pattern by metaplastic growth processes. Metaplastic carcinomas are a hetero- geneous groups of tumors which are characterized by combination of adenocarcinoma with dominant areas of spindle cell, squamous, and/or mesenchymal differentiation. The heterologous mesenchymal elements range from focal benign areas to frank sarcomas like osteosarcomas, chondrosarcomas, rhabdomyosarcoma, fibrosarcoma or liposarcomas, among which osseous and cartilaginous metaplasia are the most commonly encountered. ${ }^{2}$

CASE REPORT: A 48yrs old female had swelling in the left breast for 2 months duration. Fine needle aspiration cytology was done for the swelling. An impression of atypical cells seen in cytology was given (Figure 1). A frozen section was done which was reported as positive for malignant cells. Following which a modified radical mastectomy was done.

Grossly the lesion was in the upper inner quadrant measuring $6 \times 5 \times 4 \mathrm{~cm}$. The lesion was solid in nature and had ill-defined margins (Figure 2). On microscopy H\&E sections, showed aninfiltrating carcinoma (Figure 3) mixed with heterologous mesenchymal elements which had areas of cartilage differentiation (Figure 4). The cartilaginous areas showed malignant transformation with nuclear atypia (Figure 5), pleomorphism and atypical mitosis. A final diagnosis of metaplastic carcinoma was given. Nottinghams score was assessed in which the score for glandular differentiation was 2(10- 
$75 \%$ of tumor areas forming glandular /tubular structures), score for nuclear pleomorphism was 3(vesicular nuclei with prominent nucleoli exhibiting marked variation in size and shape), score for mitotic rate was $3\left(>8\right.$ mitosis $/ 10 \mathrm{~mm} .{ }^{2} \mathrm{~A}$ total grade of 3 was given (scores $\left.8 \& 9\right)$. The pathological staging was pT3 (tumor $>5 \mathrm{~cm}$ ), pN0 (no regional lymph node metastasis identified-total no of nodes examined was 10 and total no of positive nodes was 0 ), cM0 (Clinically no metastasis identified). A final impression of pT3pN0cM0 Nottinghams grade 3 metaplastic carcinoma with chondrosarcomatous differentiation, Margins free of tumor was given. Immunohistochemistry was not performed as the chondrosarcomatous differentiation was very clearly evident in Hematoxylin \& Eosin staining.

DISCUSSION: Metaplastic carcinomas of the breast comprise less than $1 \%$ of all invasive carcinomas. They are a heterogeneous group of malignant breast tumors in which a part or all of carcinomatous epithelium gets converted into a non-glandular (Metaplastic) growth process. ${ }^{1}$ Grossly they are usually well delineated and are often solid on cut surface. ${ }^{1}$ Squamous or chondroid differentiation is seen as pearly white to firm glistening areas on cut surface. ${ }^{2}$ Single or multiple small cysts may be seen on the cut surface of larger squamous tumours. Microscopically the WHO has proposed the classification of metaplastic carcinomas as follows (Table 1):

\begin{tabular}{|c|}
\hline WHO CLASSIFICATION OF METAPLASTIC CARCINOMAS \\
\hline Purely epithelial \\
Squamous \\
-Large cell keratinizing \\
-Spindle cell \\
-Acantholytic \\
Adenocarcinoma with spindle cell proliferation \\
Adenosquamous, including mucoepidermoid \\
Mixed epithelial and mesenchymal \\
-Carcinoma with chondroid metaplasia \\
-Carcinoma with osseous metaplasia \\
-Carcinosarcoma \\
TABLE 1
\end{tabular}

Data were derived from Tavassoli and Devilee, 32003.

Cartilaginous lesions of the breast are very rare. Benign tumors, like pleomorphic adenoma and chondrolipoma may contain benign chondroid tissue, but the presence of even focal malignant chondroid tissue is very rare. In primary breast tumor, the chondrosarcomatous lesions can occur in three forms: They can be a pure chondrosarcoma, or as a heterologous component in a malignant phyllodes tumor or as a chondrosarcomatous differentiation in Metaplastic carcinoma. In less than $5 \%$ of all breast carcinomas, part or whole of the carcinomatous epithelium gets transformed into a non-glandularmesenchymal tissue by metaplastic processes. ${ }^{2-3} \mathrm{~A}$ case of malignant phyllodes with chondrosarcomatous overgrowth was reported in which the chondrosarcomatous component constituted more than $80 \%$ of the tumor. ${ }^{4}$ If not thoroughly sampled for areas of characteristic leaflike pattern orareas of benign ductal epithelium, the malignant phyllodes tumor could have been be 
misdiagnosed as a pure chondrosarcoma. In another case there was extensive cartilaginous differentiation with many areas showing chondrosarcoma features. This was reported as metaplastic carcinoma with extensive chondroid differentiation (Chondroid carcinoma).Hence complete and thorough tumor sampling is very important.

Immunohistochemistry for the epithelial markers, like EMA and cytokeratin is essential to rule outthe pure sarcomas. Immunohistochemistry for the smooth muscle actin is helpful in distinguishing metaplastic carcinoma with a chondroid differentiation from the myoepithelial carcinoma which has chondroid matrix. ${ }^{5-7}$ Because metaplastic carcinomas often seem to originate from the poorly differentiated ductal carcinomatous element these tumors are usually negative for the estrogen and progesterone receptor. ${ }^{8}$ They also rarely express her2neu receptor. ${ }^{9}$

Only few studies are available of the molecular pathology in the metaplastic carcinomas. One study showed that the activation of Want signal pathway was very common in metaplastic carcinoma.10-11 In another study done by Leibl S et al b- catenin, WISP3 and APC gene mutations was observed in 11 out of the 27 cases of metaplastic carcinomas. ${ }^{12}$ The same study quoted that $70 \%$ of themetaplastic carcinomas, have EGFR overexpression and amplification. ${ }^{12}$ Some studies stated that metaplastic carcinomas are like basal tumors and in their study $57 \%$ of metaplastic carcinomas exhibited EGFR overexpression. All of these studies are of value as they may be used for targeted therapy inpatients with metaplastic carcinoma. ${ }^{13-15}$

CONCLUSION: Metaplastic carcinomas has to be kept in the differential diagnosis of all chondroid lesions of the breast. A definitive diagnosis in core biopsies cannot be reached due to tumor heterogeneity. Extensive sampling is essential to rule out sarcomatous change in the mesenchymal elements. Immunohistochemistry for cytokeratin and SMA may help for confirming the diagnosis. The recent molecular advances should be kept in mind as they may pave way for targeted therapy. This case is presenteddue to the rarity of the tumorand hence reporting it will help surgeons in the diagnosis.

\section{REFERENCES:}

1. Shilpa Rungta, MD; Celina G. Kleer, MD. Metaplastic Carcinomas of the Breast-Diagnostic Challenges and New Translational Insights. Arch Pathol Lab Med 2012:136; 896-900.

2. Yee-Jeong Kim, Hyo-Seob Shim, Hyde Lee, and Woo-Hee Jung1. Metaplastic Carcinoma with Extensive Chondroid Differentiation in the Breast (Chondroid Carcinoma) Yonsei Medical Journal 2006: 47; p 259-263.

3. Tavassoli .FA, Devilee P, eds. Pathology and Genetics of tumors of the Breast and Female Genital Organs. World Health Organisation Classification of tumors 2003:vol4; 37-38.

4. Vinay Singhal, Chintamani and John M Cosgrove. Osteogenic sarcoma of the breast arising in a cystosarcomaphyllodes-a case report and review of the literature. Journal of Medical Case Reports 2011: 5; 293.

5. G M Tse, P H Tan, T C Putti, P C W Lui, B Chaiwun, B K B Law. Metaplastic carcinoma of the breast-a clinic pathological review. J ClinPathol 2006:59; 1079-1083.

6. IsilGünhan, Bilgen, AysenurMemis, EsinEminÜstün, Osman Zekioglu, NecmettinÖzdemir. Metaplastic Carcinoma of the Breast-Clinical, Mammographic, and Sonographic Findings with Histopathologic Correlation. American journal of research2002:178; 1421-1425. 


\section{CASE REPORT}

7. Dewasi N, Bhattacharya D, Sarkar PG, Das M, Ghosh S, Ghosh TK. Metaplastic carcinoma of breast. Journal of Pathology of Nepal 2014: Vol. 4; 594-596.

8. Yang WI, Choi IJ, Kim HO, Lee KS. Demonstration of estrogen receptor by immunohistochemical staining in paraffin sections of breast carcinoma. Yonsei Med J 1991; 32: 117-25.

9. P. J. Barnes, R. Boutilier, D. Chiasson, and D. Rayson: Metaplastic breast carcinoma: clinicalpathologic characteristics and HER2/neu expression: Breast Cancer Research and Treatment (2005) 91: 173-178.

10. J S Reis-Filho, et al: Metaplastic breast carcinomas are basal-like tumours: Histopathology 2006, $49,10-21$.

11. Hayes MJ, Thomas D, Emmons A, Giordano TJ, Kleer CG. Genetic changes of the Wnt pathway genes are common events in metaplastic carcinomas of the breast. Clin Cancer Res. 2008:14;4038-4044

12. Leibl S, Moinfar F. Metaplastic breast carcinomas are negative for Her-2 but frequently express EGFR (Her-1)- potential relevance to adjuvant treatment with EGFR tyrosine kinase inhibitors? J ClinPathol. 2005; 58 (7):700-704.

13. Rouzier R, Perou CM, Symmans WF et al. Breast cancer molecular subtypes respond differently to preoperative chemotherapy. Clin. Cancer Res. 2005; 11; 5678-5685.

14. Popnikolov NK, Ayala AG, Graves K, Gatalica Z. Benign myoepithelialtumors of the breast have immunophenotypic characteristics similar to metaplastic matrix-producing and spindle cell carcinomas. Am. J. Clin. Pathol. 2003; 120; 161- 167.

15. Perou CM, Sorlie T, Eisen MB et al. Molecular portraits of human breast tumours. Nature 2000; 406; 747-752.

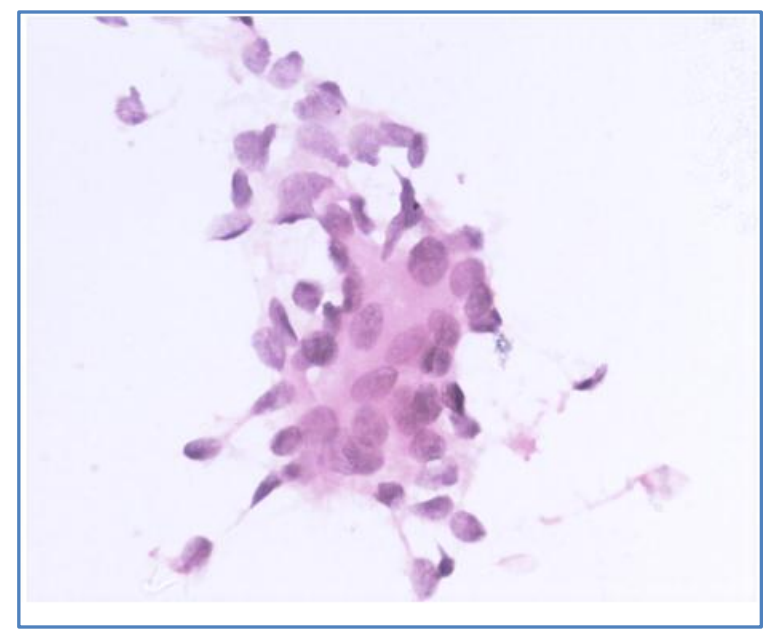

Fig. 1: H\&E 200x A typical cells present-FNAC 


\section{CASE REPORT}

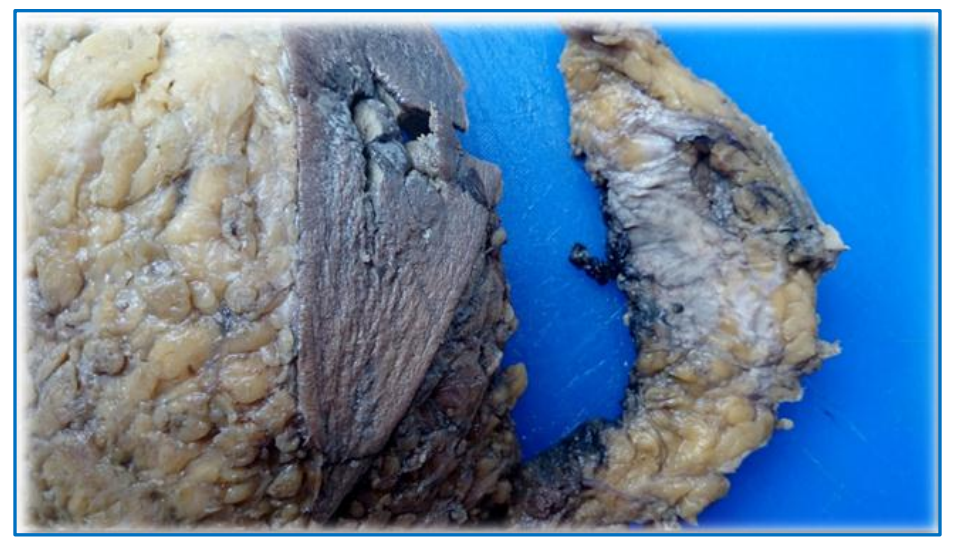

Fig. 2: Cut surface showing an illdefined grey white tumor

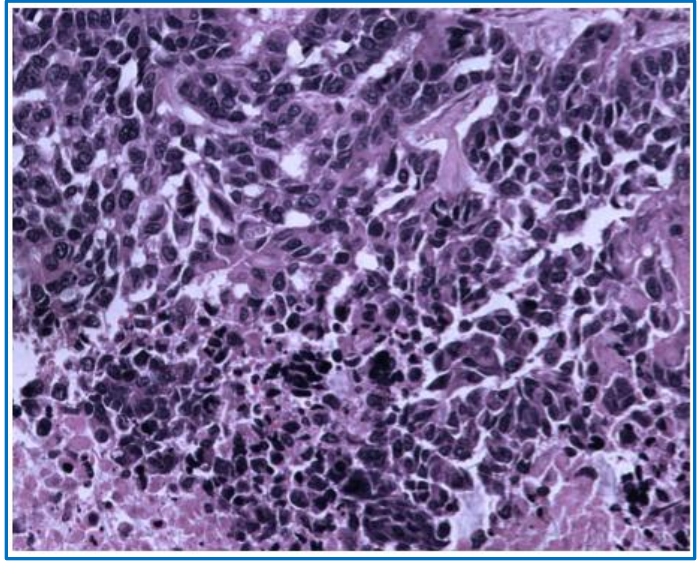

Fig. 3: H\&E 200x Infiltrating carcinoma

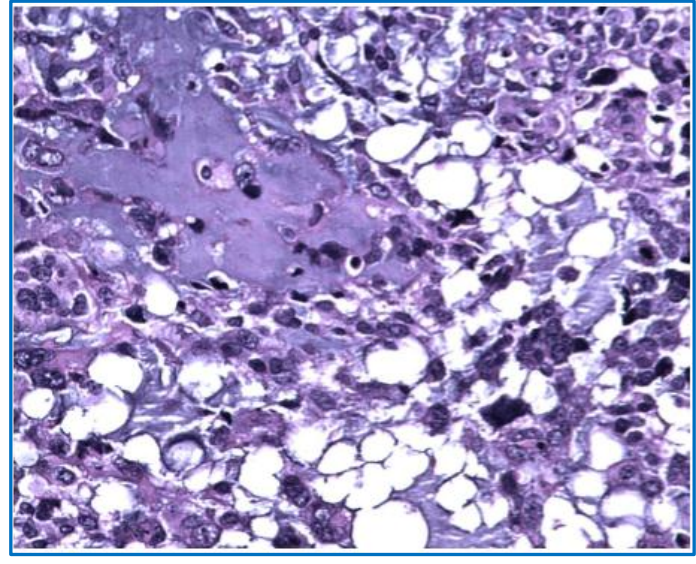

Fig. 4: H\&E 200x Chondroid areas

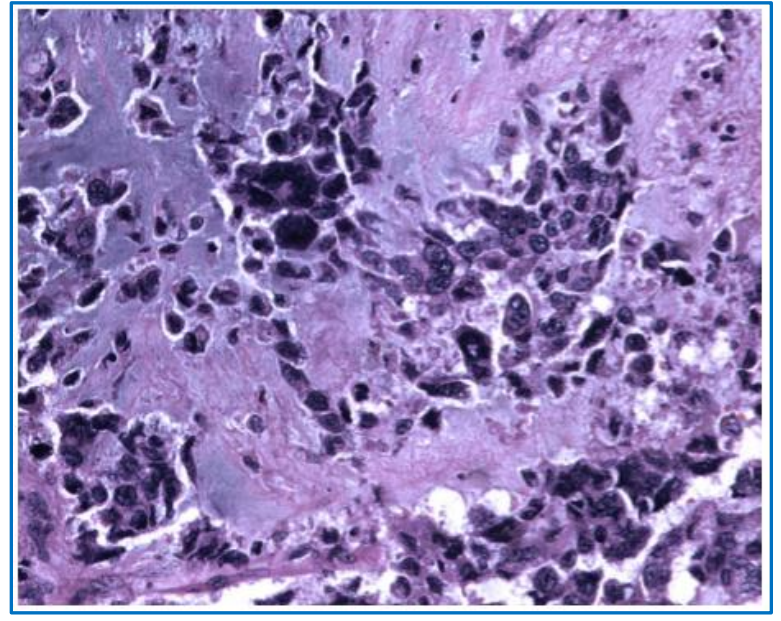

Fig. 5: H\&E 400x Chondroid areas showing malignant transformation 


\section{CASE REPORT}

\section{AUTHORS:}

1. Prema Devi E.

2. Susruthan M.

3. C. D. Narayanan

4. N. Priyathershini

5. J. Thanka

\section{PARTICULARS OF CONTRIBUTORS:}

1. Final Year Post Graduate, Department of Pathology, Sri Ramachandra University, Porur, Chennai.

2. Assistant Professor, Department of Pathology, Sri Ramachandra University, Porur, Chennai.

3. Professor, Department of Surgery, Sri Ramachandra University, Porur, Chennai.

FINANCIAL OR OTHER COMPETING INTERESTS: None
4. Assistant Professor, Department of Pathology, Sri Ramachandra University, Porur, Chennai.

5. HOD, Department of Pathology, Sri Ramachandra University, Porur, Chennai.

\section{NAME ADDRESS EMAIL ID OF THE CORRESPONDING AUTHOR:}

Dr. Prema Devi E, Sri Ramachandra University, Porur, Chennai.

E-mail: premadevie@gmail.com

Date of Submission: 25/02/2015.

Date of Peer Review: 26/02/2015.

Date of Acceptance: 07/03/2015.

Date of Publishing: 19/03/2015. 